\title{
PALAEOSEISMOLOGICAL INVESTIGATION OF THE GYRTONI FAULT (THESSALY, CENTRAL GREECE)
}

\author{
Tsodoulos I. ${ }^{1}$, Chatzipetros A. ${ }^{2}$, Koukouvelas I. ${ }^{3}$, Caputo R. ${ }^{4}$, Pavlides S. ${ }^{2}$, \\ Stamoulis K. ${ }^{1}$, Gallousi C. ${ }^{1}$, Papachristodoulou C. ${ }^{1}$, Ioannides K. ${ }^{1}$, Belesis A. ${ }^{3}$, \\ Kremastas E. ${ }^{2}$ and Kalyvas D. ${ }^{3}$ \\ ${ }^{1}$ University of Ioannina, Department of Physics, 45110, Ioannina, Greece, itsodoul@cc.uoi.gr, \\ kstamoul@cc.uoi.gr,kioannid@cc.uoi.gr,gallousi@upatras.gr,xpapaxri@cc.uoi.gr \\ ${ }^{2}$ Aristotle University of Thessaloniki, Department of Geology, 54124, Thessaloniki, Greece, \\ ac@geo.auth.gr,pavlides@geo.auth.gr,ekremast@geo.auth.gr \\ ${ }^{3}$ University of Patras, Department of Geology,26500,Patras, Greece, iannis@upatras.gr, \\ abelesis@hol.gr,dimikalyvas@gmail.com \\ ${ }^{4}$ University of Ferrara, Department of Physics \& Earth Sciences, 44122, Ferrara, Italy, \\ rcaputo@unife.it
}

\begin{abstract}
Two paleoseismological trenches were excavated across the Gyrtoni Fault in NE Thessaly and studied in order to understand the recent seismotectonic behavior of this structure. Twenty five fluvial-colluvial sediment and pottery samples from both the upthrown and the downthrown fault blocks were investigated. Optically Stimulated Luminescence (OSL) dating has been applied to date both sedimentary depositspalaeosoils and pottery fragments. Paleoseismological analysis of the two trenches indicates evidence of three surface faulting events in the time span between $1.42 \pm$ $0.06 \mathrm{ka}$ and $5.59 \pm 0.13 \mathrm{ka}$. The observed vertical displacement per event of $\sim 0.50 \mathrm{~m}$ corresponds to an $M w 6.5 \pm 0.1$ earthquake. An average fault slip rate of $0.41 \pm 0.01$ $\mathrm{mm} / \mathrm{yr}$ and an average recurrence of $1.39 \pm 0.14 \mathrm{ka}$ for earthquakes were estimated. The results documented the activity of the fault and since the return period from the most recent event (minimum age $1.42 \pm 0.06 \mathrm{ka}$ ) has expired, the possibility for reactivation of this active structure in the near future should be included in Seismic Hazard Assessment.
\end{abstract}

Keywords: Active Fault, Paleoearthquakes, Tyrnavos basin, Larissa, Thessaly.

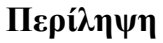

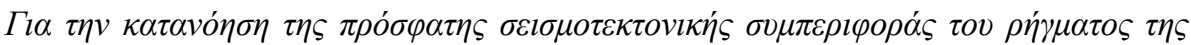

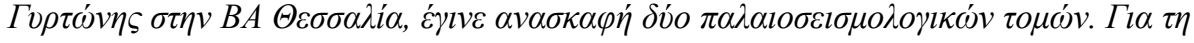

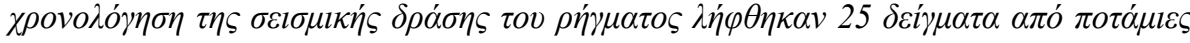

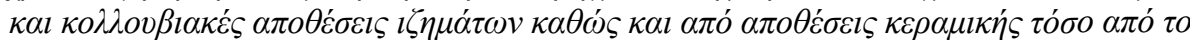

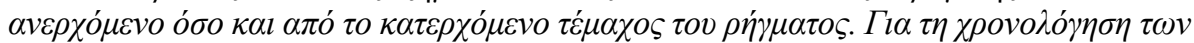

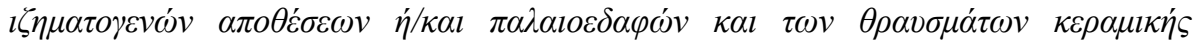

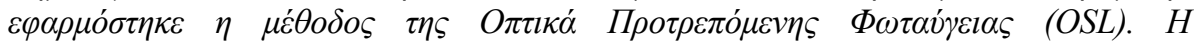

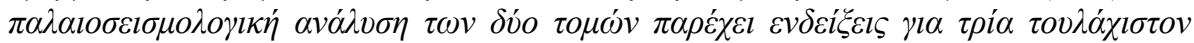

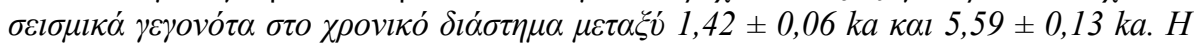

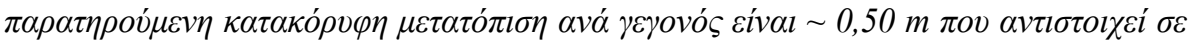




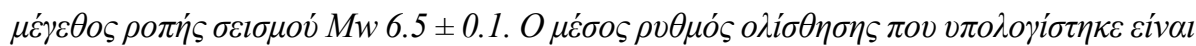

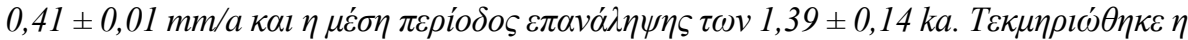

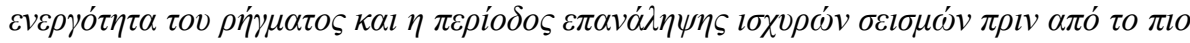

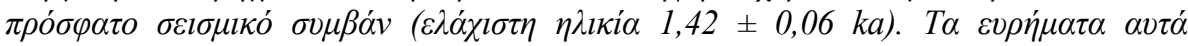

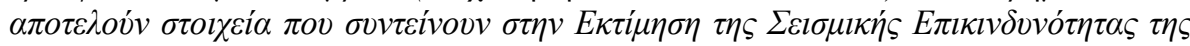
$\pi \varepsilon \rho i o \chi \dot{\eta} \varsigma$.

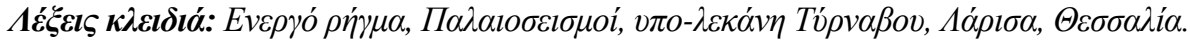

\section{Introduction}

The Gyrtoni Fault (GF) is an ESE-WNW-trending, south-dipping normal fault that defines the northeastern boundary of the Quaternary Tyrnavos Basin (Caputo et al., 1994) and is located at a distance of $\sim 13 \mathrm{~km}$ from the Larissa, one of the largest cities of Greece. The GF was initially described by Schneider (1968) as an important morphological feature (Gyrtoni terrace) affecting the northern Larissa Plain. It was recognized as an active tectonic structure by Caputo (1990) and Caputo and Pavlides (1993). The surface expression of the fault is composed of two right stepping en-echelon fault segments (Caputo, 1995; Caputo et al., 1994) (Fig. 1).

The Tyrnavos Basin is dominated by E-W to ESE-WNW-trending normal faults developed during Middle-Late Pleistocene as a result of the roughly N-S lithospheric extension affecting the Aegean region (Caputo, 1990; Caputo and Pavlides, 1993), which is still active as denoted by the recent seismicity of the area (Ambraseys and Jackson, 1990; Caputo and Pavlides, 1993; Caputo et al., 1994; Papaioannou, 1988). The west fault segment of the GF offsets Late Pleistocene floodplain deposits (or Niederterrasse, Schneider, 1968) in the footwall block, from Holocene alluvial deposits (Gyrtoni alluvium, Demitrack, 1986; van Andel et al., 1990). The morphological expression of the west fault segment is a south-facing $~ 12$-m-high, wash-controlled, degraded fault escarpment, visible on satellite images and aerial photographs as a corrugated structure (Fig. 2b). Two perpendicular topographic profiles, using a portable GPS receiver, were constructed, across the surface trace of the fault directly (scarp profile) east and west of the second trench, respectively (Fig. 2). The topographic profiles exhibit breaks in slope, which is commonly related to "composite fault scarps" created by multiple faulting events. We interpreted these inflections in slope mainly as the result of earlier faulting events rather than of erosional origin, on the basis of the multiple faulting events observed in the excavated trenches. The profile data indicate a scarp height of $12 \mathrm{~m}$, with a width of $120-130 \mathrm{~m}$, and a maximum scarp-slope angle of $c a .7^{\circ}$. The cumulative surface offset is $12 \mathrm{~m}$, based on original surfaces (Fig. 2a).

The geological research and the applied geophysical techniques (Caputo et al., 2003; Oliveto et al., 2004) have been employed to qualitatively and quantitatively describe the GF. Based on neotectonic, morphotectonic and seismotectonic research a possible long-term slip rate lower than $0.1 \mathrm{~mm} / \mathrm{a}$ was proposed, ranking the GF as class $\mathrm{C}$, according to the classification system of the Research Group of Active Faults of Japan (RGAFJ, 1992).

The understanding of the seismotectonic behavior of this tectonic structure in terms of slip rate on fault, recurrence interval and date of past earthquakes, is of great importance considering that northern Thessaly represents an important seismic gap within the broader Aegean Region (Caputo, 1995).

\section{Materials and Methods}

\subsection{Paleoseismologic trenches across the Gyrtoni Fault}

To study the paleoseismic activity and history of the GF, two single-slot (California-style) trenches were excavated across the fault scarp at the central section of the west fault segment of the GF (Fig. 1). The first trench (G1) dug in 2012 as an exploratory trench was $27 \mathrm{~m}$-long, $2 \mathrm{~m}$-wide and up to 4 m-deep (Fig. 3). 

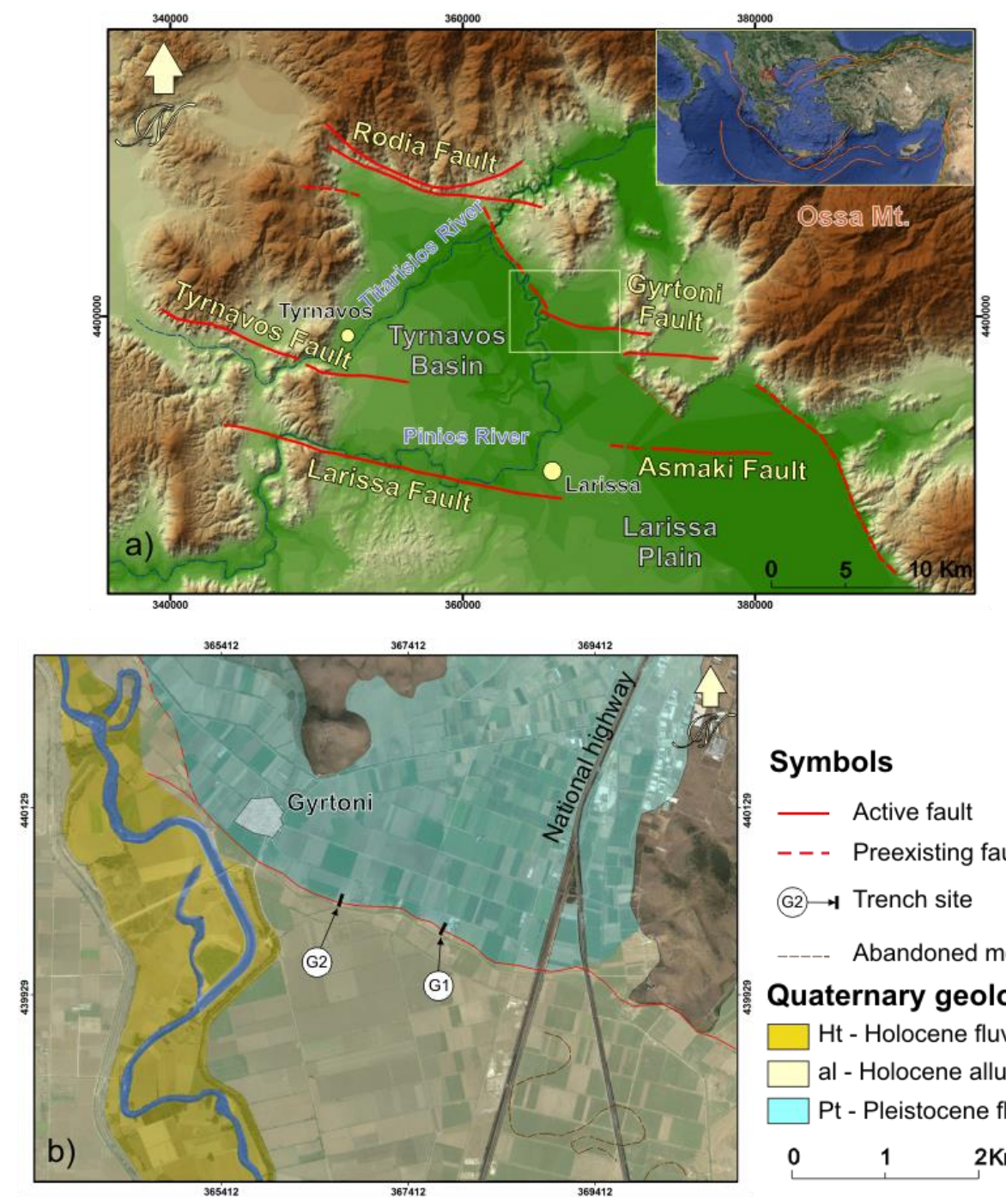

\section{Symbols}

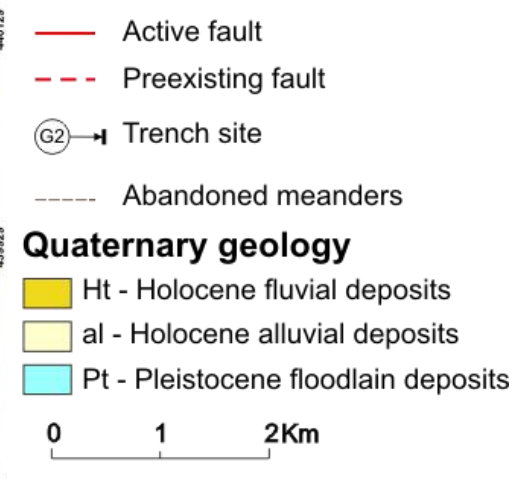

Figure 1 - a) Digital Elevation Model with hill-shading relief of the Tyrnavos Basin showing the main structural features (faults adopted from Caputo et al., 1994). b) Simplified geological map (IGME, 1985; Caputo, 1990) of the study area, and the locations of the two trenches. Images taken form GoogleEarth.

The second trench (G2) was $9 \mathrm{~m}$-long, 2 m-wide and up to $3 \mathrm{~m}$-deep, and was excavated during 2014 approximately $1 \mathrm{~km}$ to the west of the first trench (Fig. 1 and 4). The walls of the trenches were cleaned, gridded with a $1 \mathrm{~m}$ by $1 \mathrm{~m}$ string grid, sedimentary boundaries and structural features were mapped in detail and photographed, and samples were collected for age determination. Both trenches intersect the fault zone which separates a series of well stratified, thick beds of abandoned floodplain deposits exposed on the footwall block, from fluvial and colluvial deposits on the hanging wall block. 


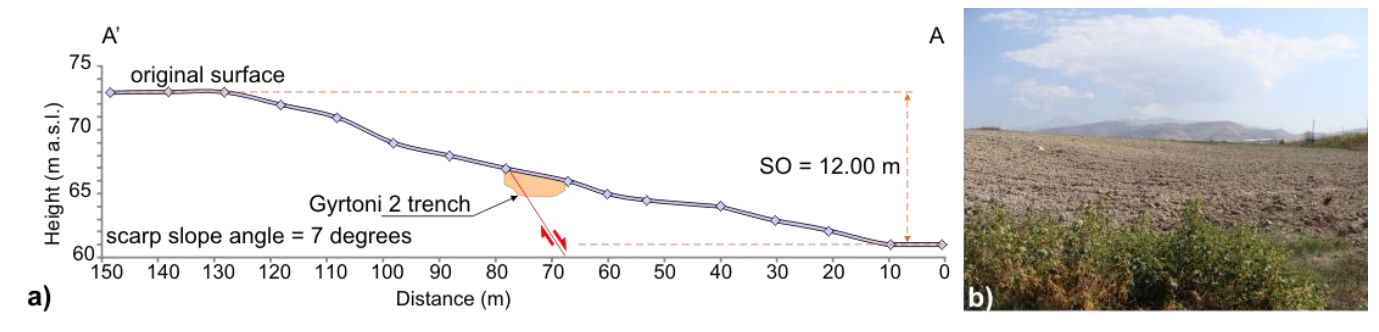

Figure 2 - (a) Topographic profile at the second paleoseismic site located east ( $A^{\prime}$-A) of the trench G2. Profile was surveyed perpendicular to the local surface trace of the fault scarp. SO: Surface offset. (b) Field view of the fault scarp from the west.

The exposed sedimentary deposits are distinguished in units and labeled by numbers, whereas subunits are labeled with lower-case letters, based on their inferred age and stratigraphic position. Although exposed sedimentary units on both trenches are similar, labeling is independent in each trench.

\subsection{Trench tectono-stratigraphy}

\subsubsection{Trench Gyrtoni 1 (G1)}

Figure 3 shows the log of the east trench wall. Five lithostratigraphical units are distinguished in the upthrown block of the trench (Units 1- 5, floodplain deposits, Late Pleistocene; Fig. 3). The stratigraphic sequence of the upthrown block is slightly dipping towards the north. All unit boundaries are erosive. A brief description of the exposed units is given below (from oldest to youngest). Unit 1 is a 2.4 m-thick, massive, greenish-grey silty clay undeformed layer, with small, scattered, carbonate caliche nodules at the upper part of the unit. Unit 2, up to $1 \mathrm{~m}$-thick, consists of discontinuous, wavy, non-parallel laminated to greyish-black clay. Unit 3 is a $50 \mathrm{~cm}$-thick, crude parallel to sub-parallel laminated yellowish-grey silty clay, with well-developed caliche glaebules at the uppermost part of the unit. The sedimentological characteristics of units 1, 2 and 3 suggest overbank deposition on an alluvial plain. Unit 4, up to $90 \mathrm{~cm}$-thick, corresponds to a channel-fill deposit. It consists of moderately sorted, sub-rounded to sub-angular small pebbles, with a yellowish fine to very coarse sand matrix. The structure of the unit is characterized by well-defined wavy to planar parallel bedding and bi-directional cross-lamination in the lower part. Unit 5 is a $30 \mathrm{~cm}$-thick, discontinuous planar, non-parallel, bedded brownish-grey silty clay, with scattered angular granules to small pebbles.

On the downthrown block, two main units with a maximum exposed thickness of $2.3 \mathrm{~m}$ have been differentiated (fluvial-colluvial deposits). Unit 6 (alluvium) is a massive greyish-brown silty clay with scattered angular to sub-angular granules and small pebbles. Buried pottery found within unit 6 (21 - 22 m; Fig. 3), 2 m below the surface, was attributed possibly to the Middle Bronze Age (2000 - 1600 B.C.) (Dr. A. Vlachopoulos, pers. comm.). The upper part of this unit overlaps the lower fissure fill (unit f2). Unit 7 (Early Pinios alluvium), up to $1 \mathrm{~m}$ thick, is a massive greyishbrown silty clay with interspersed pottery fragments situated closest to the middle and the lower part of the unit. An erosional surface was observed at the boundary between units 6 and 7 . The grain size and the massive structure, with no macroscopic stratification, of the above described units are interpreted as fluvial deposits accumulated by flooding (van Andel et al., 1990) of an abandoned meandering segment of Pinios River that flowed close to the Gyrtoni escarpment in the area of the former Nessonis Lake (Fig. 1b) (Caputo et al., 1994). The part of units 6 and 7 that is close to the fault zone has also colluvial origin. 


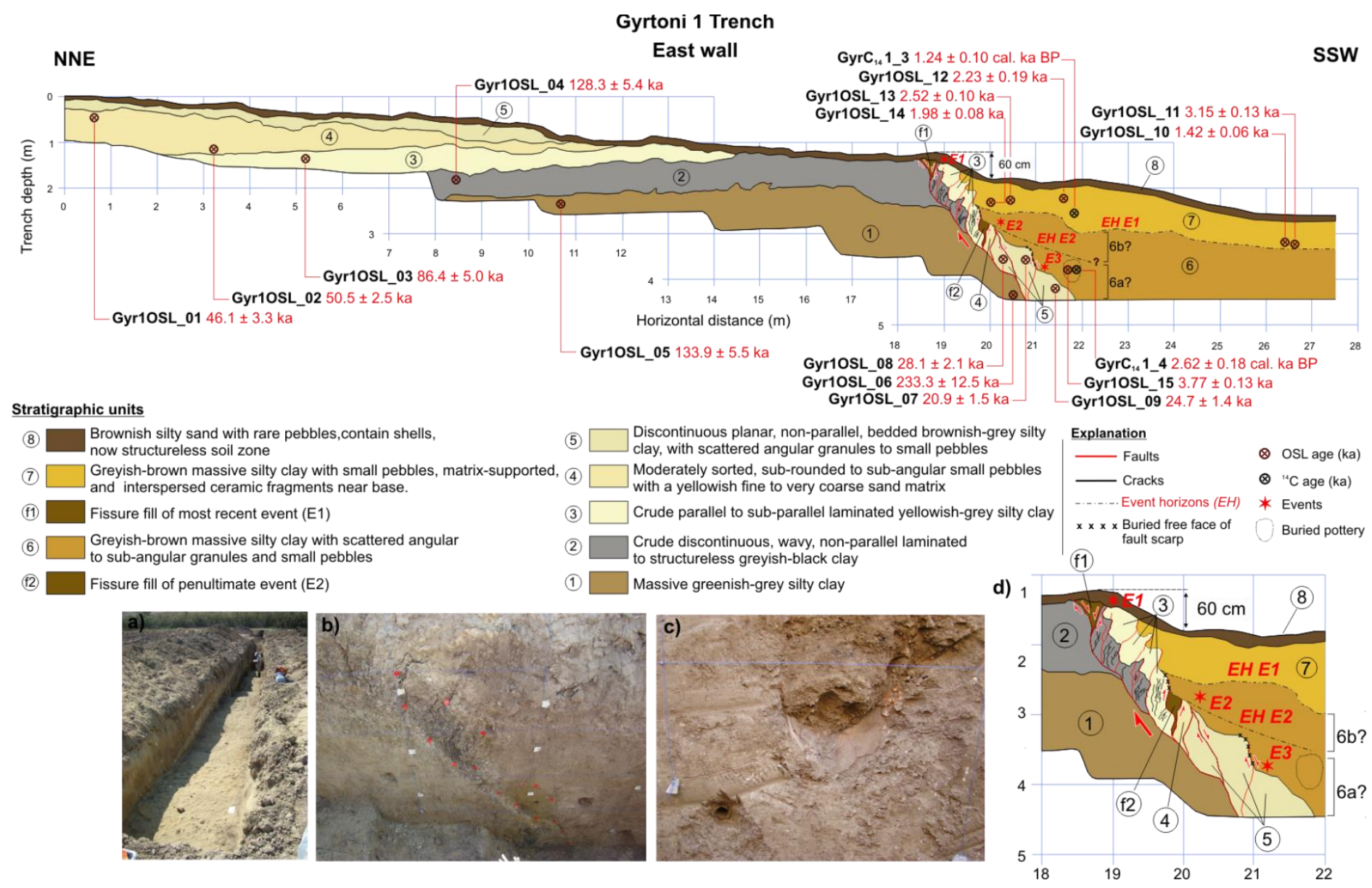

Figure 3 - Log of the east wall of trench G1 excavated across the fault scarp. OSL ages are expressed as thousands of years before 2014 AD. Radiocarbon dates are calibrated to calendar years and 64 years were added in order to give them the same reference point as the luminescence ages. (a) View of the trench from the north. (b) View of the east wall of the trench. (c) A close-up photograph showing the buried pottery. (d) Enlarged log of the fault zone. Trench location is shown in Fig. 1. 
In the fault zone, we distinguished two fissure fills (units f1 and f2, Fig. 3) adjacent to the main fault. The two fissure fills were identified on the basis of distinctive changes in texture and color. Unit f2 corresponds to the older exposed fissure fill in the fault zone and it consists of structureless yellowish-grey silty sand. Unit f1 consists of chaotic dark greyish clay with open cracks. The random fabric and the lithology of the filling material suggest deposition into the fissure of material derived mainly from unit 2 , probably as a saturated mass.

The described units are covered by a ploughed, laterally continuous brownish silty sand soil (unit 8). Unit 8 corresponds to the current A horizon (soil).

\subsubsection{Trench Gyrtoni 2 (G2)}

Figure 4 shows the log of the east wall of trench G2. Three lithostratigraphical units are distinguished in the upthrown block of the trench (Units 1 to 3, Fig. 4). Unit 1 is the oldest exposed unit and it consists of discontinuous, planar and parallel bedded grey clay, progressively dipping to the south close to the fault zone. Unit 2 is a multi-storey palaeochannel belt up to $75 \mathrm{~cm}$-thick. It is subdivided in a lower subunit $2 \mathrm{a}$, which corresponds to channel deposit, made up of well defined wavy to planar parallel bedded and south-directional cross-lamination, yellowish brown, fine to very coarse sand with sub-angular, moderately sorted, small pebbles; subunit $2 \mathrm{~b}$ is a lenticular structure of greyish silty clay, probably a small size oxbow-lake deposit; and subunit $2 \mathrm{c}$ is the upper channel deposit, overlaying subunits $2 \mathrm{a}$ and $2 \mathrm{~b}$, consisting of draped, parallel bedded yellowish brown medium to very coarse sand containing sub-rounded granules and shell fragments. Unit 3 is an $85 \mathrm{~cm}$-thick, crude parallel to sub-parallel laminated yellowish-grey silty clay, with a thick calcrete horizon at the uppermost part of the unit, suggesting a well-developed soil profile. The calcrete horizon is progressively bents towards the fault zone. We interpreted unit 3 as a floodplain deposit.

On the downthrown block, two main sedimentary units were distinguished with a maximum exposed thickness of $3 \mathrm{~m}$ (Figs. 4). Unit 4 corresponds to a $60 \mathrm{~cm}$-thick scarp derived colluvial deposit, composed of greenish grey silty sand. Unit 5, at least $2.4 \mathrm{~m}$ thick, is greyish-brown massive silty clay with scattered angular to sub-angular granules to small pebbles. Pottery fragments from different time periods (from $20^{\text {th }}$ century BC to $15^{\text {th }}$ century AD) were found.

Similar to trench G1, two discrete fissure fills have been mapped at the east wall of the trench, each corresponding to a surface-faulting earthquake (units f1 and f2, Fig. 4).

A laterally continuous, ploughed, brownish silty sand soil with rare pebbles (unit 6 on Fig. 4) is developed on the upper part of the trench G2 and it corresponds to the present A horizon.

\subsubsection{Structure}

Both excavated trenches exposed a 2-m-wide fault zone composed of synthetic and antithetic normal fault strands. The secondary and the antithetic fault strands were merged to the main fault plane which turns into a single shear zone, dipping $57-60^{\circ}$ to the south toward the base of the trenches (Figs. 3 and 4). Striations found on the fault plane at the lower part of the east wall of trench G2, indicate pure dip-slip movement $\left(\sim 200^{\circ} \mathrm{S}\right)$. The fault zone is composed of displaced and dragged blocks of relatively intact and occasionally rotated (around $33^{\circ}$ down-to-the-south) sedimentary units from the up-thrown block (Fig. 4), probably by frictional drag along the fault plane, and fissure fill deposits.

\subsection{Geochronology}

\subsubsection{Luminescence dating}

Optically Stimulated Luminescence (OSL) dating (Huntley et al., 1985) was used to date samples from this area. Nine samples were collected from the five distinct lithologic units exposed on the upthrown fault block of trench G1 (Fig. 3) and three samples from the exposed units of the upthrown fault block of trench G2 (Fig. 4). 
Gyrtoni 2 Trench

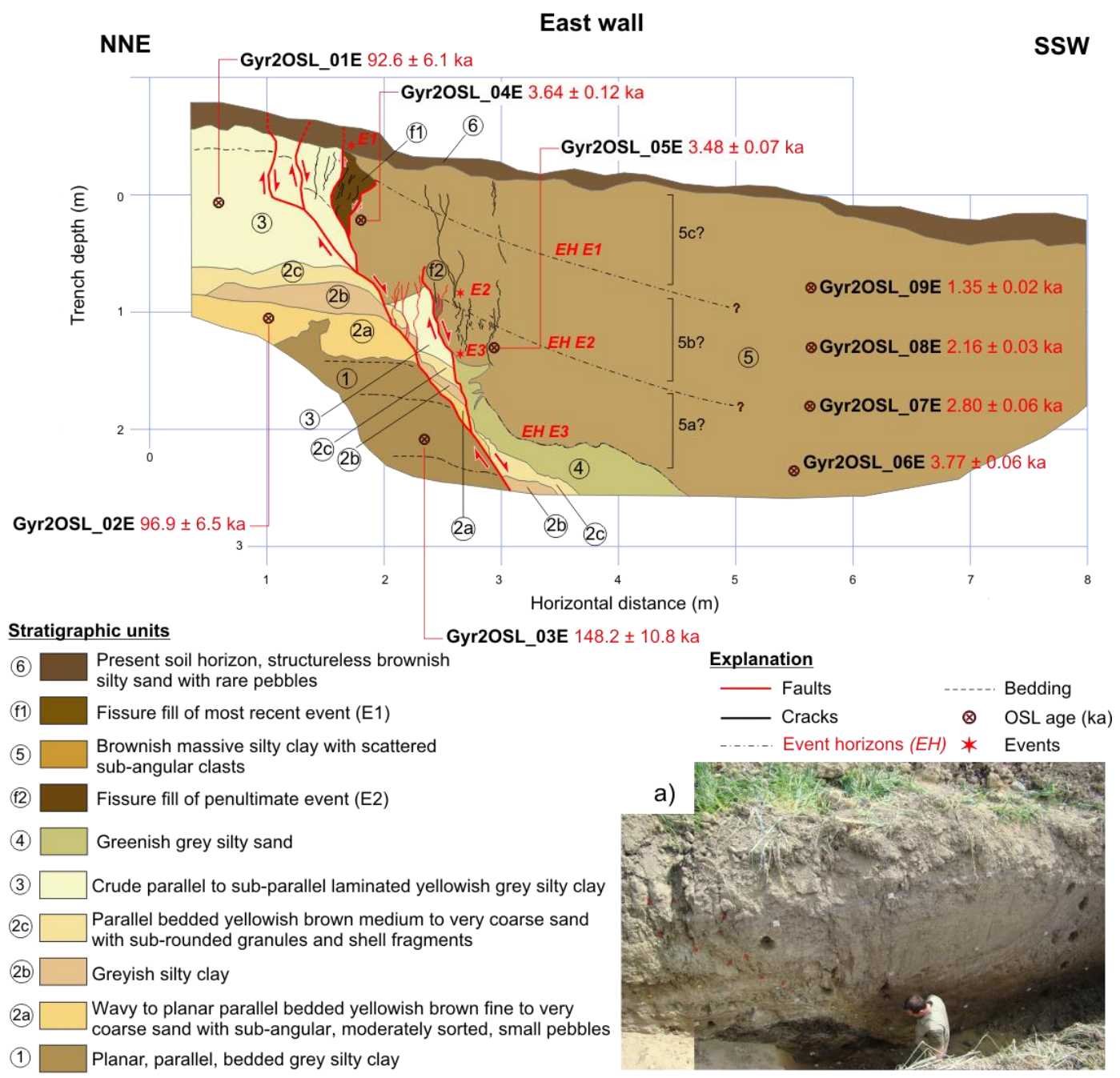

Figure 4 - Log of the east wall of trench G2 excavated across the fault scarp. OSL ages are expressed as thousands of years before $2014 \mathrm{AD}$. (a) View of the east wall of the trench. Trench location is shown in Fig. 1.

Also, eight sediment samples and five pottery fragments were collected from the four distinct lithologic units exposed on the downhrown fault blocks of the two trenches to constrain the timing of the earthquake events (Figs. 3 and 4). One sediment sample and four pottery fragments were collected from the silty clay unit 7 and pieces from the buried pottery that was found in the lower part of the silty clay unit 6 of trench G1 (Fig. 3). Four sediment samples were collected in a vertical sequence in order to establish an age trend with depth and two from different parts close to the fault zone of unit 5 from trench G2 (Fig. 4). One additional sample was collected from the silty sand colluvial deposit unit 4 that was exposed on the west wall of the same trench.

Sample preparation and luminescence measurements were carried out at the Archaeometry Center at the University of Ioannina. OSL measurements were made on chemically purified coarse-grained quartz, using the single-aliquot regenerative-dose (SAR) protocol proposed by Murray and Wintle (2000; 2003). The purity of the quartz extract was checked using the OSL-IR depletion ratio (Duller, 2003). Luminescence measurements were performed on a Risø TL/OSL-DA-20 reader equipped with a $1.48 \mathrm{GBq}{ }^{90} \mathrm{Sr}-{ }^{90} \mathrm{Y}$ beta radiation source. The environmental dose rate for each sample was 
calculated using high-resolution gamma spectrometry. The concentrations of radionuclides were then used to calculate the dose rates using the conversion factors of Adamiec and Aitken (1998). The cosmic radiation contribution was also taken into acount (Prescott and Hutton, 1994). The calculated OSL ages are shown in Figs. 3 and 4.

\subsubsection{Radiocarbon dating}

Samples for radiocarbon dating were collected from the two trenches and were dated at the Center for Dating and Diagnostics, Department of Engineering for Innovation, University of Salento, Italy, using accelerator mass spectrometry (AMS) techniques. The delivered radiocarbon dates of the collected samples are shown in Fig. 3.

\section{Results and Conclusions}

\subsection{Paleoseismic interpretation and timing of the events}

The recognition of the most recent displacement event (E1) and the penultimate displacement event (E2) was based on the presence of filled fissures created on the base of the fault scarp during surface faulting (McCalpin 2005).

The stratigraphic evidence of the most recent surface faulting event (E1) is the younger of the two fissures fill deposits exposed in both trenches (Fig. 3 and 4). In trench G1 event E1 displaced and dragged units 2 and 3, and was immediately followed by the deposition of unit 7 . The base of unit 7 yielded an OSL age of $1.42 \pm 0.06 \mathrm{ka}$ (Gyr1OSL_10). The contact between units 6 and 7 would then correspond to the "event horizon" of event E1. As no soil horizon formed between units 6 and 7, we can infer that the deposition age of these units was close in time. Event E1 was responsible for a vertical displacement of about $0.60 \mathrm{~m}$, measured from the vertical offset of the base of unit 2, which is in agreement with the topographic offset of $0.60 \mathrm{~m}$ measured on the scarp above the fault zone (Fig. 3). In addition, in trench G2, event E1 displaced and dragged along the main fault plane, the base of unit $2 \mathrm{~b}$ by $0.60 \mathrm{~m}$, which is in agreement with the displacement estimated in trench $\mathrm{G} 1$. The fissure fill deposit (f1) observed in trench G2 was covered by the deposition of the upper part of unit 5 . Because of the massive and clayey nature of unit 5, it was not possible to distinguish the stratigraphic contact between the upper part of unit 5, which overlies the fissure, and the lower part. However, using a smoothed envelope of the fissure f1/upper part of unit 5 boundary and also considering that the fissure must be located at the base of the coseismic free face, we have drawn a dash-dotted line in Fig. 4 to show the approximate position/shape of the prefaulting surface (EH1 in Fig. 4). To achieve the closest age constraints, the age of this "inductive" event horizon (EH1 in Fig. 4) was extrapolated from the OSL age of the samples Gyr2OSL_09E and Gyr2OSL_08E. Hence, the age of the "inductive" event horizon E1 in trench G2 is bracketed by a maximum age of $2.16 \pm 0.03 \mathrm{ka}$ and a minimum age of 1.35 $\pm 0.02 \mathrm{ka}$. Consequently, based on the dates from the two trenches, the event E1 occurred after $2.16 \pm$ $0.03 \mathrm{ka}$ and before $1.42 \pm 0.06 \mathrm{ka}$ (age of unit 7, trench G1). This event could be possibly related to a historical event that occurred between $c a$ 2nd-1st century BC with a possible magnitude 6.0-6.5 (Caputo and Helly, 2005). This historical event was recognized on the basis of archaeological and architectural evidences from Larissa and nearby towns. Although, the authors stated as possible source of this event the Rodia Fault, we cannot exclude the GF.

The penultimate surface faulting event (E2) is recognized by the deposition of the second (older) fissure fill deposit (f2) in both of the two excavated trenches (Figs. 3 and 4). In trench G1, the fissure fill (f2) deposited after the faulting event E2 was subsequently covered by the deposition of the upper part of unit 6 (subunit $6 \mathrm{~b}$ ). Subunit $6 \mathrm{~b}$ represents the interseismic graben fill deposit between events E2 and E1. Consequently, the base of subunit $6 \mathrm{~b}$ corresponds to the event horizon (EH2 in Fig. 3). The approximate position/shape of the event horizon E2 was drawn in Fig. 3 in a similar way as the event horizon E1. Event E2 in trench G2 displaced and dragged units 2, 4 and the lower part of unit 5 (subunit 5a) along the southern secondary fault plane (Fig. 4). The middle part of unit 5 (subunit 5b) most likely was deposited shortly after the faulting event E2. Two samples 
(Gyr2OSL_05E and 06E) were dated from subunit 5a and provided OSL ages of $3.48 \pm 0.07$ and $3.77 \pm 0.06 \mathrm{ka}$, respectively. A similar OSL age $(3.64 \pm 0.12 \mathrm{ka})$ was provided from a sample (Gyr2OSL_04E in Fig. 4) collected from the part of unit 5 situated between the main fault plane and the secondary fault. This similarity of the ages allowed the hypothesis that subunit 5a was faulted and displaced along the secondary fault plane during the penultimate event (E2). Accordingly, these ages provide a maximum limiting age for the event E2. Further support for this hypothesis comes from the buried pottery found in trench G1 (Fig. 3) inside the lower part of unit 6 (subunit 6a). Subunit 6a was deposited after a previous event (E3) and before the event E2 (Fig. 3). The estimated OSL age of this pottery is $3.77 \pm 0.13 \mathrm{ka}$ (Gyr1OSL_15). The vertical displacement during the surface faulting event E2 could not be estimated using offset stratigraphic units. In trench G2 a cumulative vertical displacement of $1.70 \mathrm{~m}$ was measured from the vertical offset of the top of unit 2b. Subtracting the event E1 displacement $(0.60 \mathrm{~m})$ and the event E3 minimum displacement $(0.50$ $\mathrm{m}$ ) yields a value of $0.60 \mathrm{~m}$ for the event E2. However, this displacement value could be minimum because offset units were affected by near-fault drag. Event horizon E2 in trench G2 may be placed, similar to event horizon E2 in trench G1, close to the top of the older fissure fill (f2). Thus, the second event occurred somewhere after $3.77 \pm 0.06 \mathrm{ka}$ and before $2.16 \pm 0.03-2.80 \pm 0.06 \mathrm{ka}$, most likely before $2.80 \pm 0.06 \mathrm{ka}$.

An earlier surface faulting event (E3) was recognized within trench G1, as unit 5 was displaced by the southernmost secondary fault (Fig. 3), which was subsequently sealed by the deposition of the lower part of unit 6 (subunit $6 \mathrm{a}$ ), which contained the buried pottery. We measured $0.5 \mathrm{~m}$ of vertical, down-to-the-south stratigraphic displacement using the top of unit 5, for this event. However, this displacement value could be minimum because the top of unit 5 probably experienced some erosion after the faulting event. In trench G2, during the event E3, units 2 and 4 were displaced and dragged along the southern secondary fault plane (Fig. 4). The lower part of unit 5 (subunit 5a) was subsequently deposited after the event E3. The event horizon E3 may be placed at the top of unit 4 (Fig. 4). Due to the fact that no soil horizon was formed between these two units, the deposition of subunit 5a was close in time or erosion took place. Therefore, the third event occurred after $5.59 \pm$ $0.13 \mathrm{ka}$ (unit 4, collected from the west wall of the G2 trench; not shown in Fig. 4) and before 3.77 $\pm 0.06 \mathrm{ka}$ (subunits $6 \mathrm{a}$ and 5a).

The studied trenches, along the GF, expose evidences of fissure fill deposits, scarp derived colluviums, angular unconformities in the downthrown fault block stratigraphy and absence of any paleosoil horizons. Hence, the structural and stratigraphic indications in the two trenches imply that the GF scarp is the result of episodic displacement accompanied by continuous deposition without soil formation in the downthrown fault block (McCalpin 2003).

\subsection{Displacement per event and paleoearthquake magnitude}

The vertical displacements for the paleoearthquakes E1, E2 and E3, as estimated stratigraphically from the two trenches, are $0.60,0.60$ and $0.50 \mathrm{~m}$, respectively. Obviously, all events were very similar in size. This implies that GF may display a "characteristic earthquake" behavior (Schwarz and Coppersmith, 1984). For this reason, we assumed a vertical displacement for the paleoearthquake E4 of 0.50-0.60 m. Following empirical relationships between magnitude and maximum vertical displacement (Wells and Coppersmith, 1994; Pavlides and Caputo 2004) and assuming a vertical displacement of $0.50-0.60 \mathrm{~m}$ per event that was observed in our trenches as maximum; we can calculate a moment magnitude $(\mathrm{Mw})$ of the order of $6.5 \pm 0.1$. By the same token, a moment magnitude of 6.5 is consistent with a surface rapture length of $18-19 \mathrm{~km}$, which is longer than the measured length of the GF. Although, the ESE-WNW-trending GF ignore and cut-across pre-existing faults, it is possible that inherited extensional structures may locally or partially be reactivated with oblique kinematics.

Scarp profiles near the trench G2 show surface offset of $12 \mathrm{~m}$. This value is a first-order estimate of the vertical displacement, but as noted previously, the fault scarp is degraded, so this surface offset is a minimum value. The vertical displacement for the three most recent events is well constrainted 
and similar. The cumulative vertical displacement for these events, as measured on the basis of stratigraphic correlation in trench G2, is $1.70 \mathrm{~m}$. These three events represent the $15 \%$ of the surface offset of the GF. Therefore, the displacement of the fault scarp could have been produced by as many as twenty past faulting events.

\subsection{Recurrence interval and slip rate}

Although the timing of the three most recent events (E1, E2 and E3) is not very well constrained due to the massive character of the units 6 and 5 in trenches G1 and G2, respectively, we assumed that two complete earthquake cycles have occurred between $5.59 \pm 0.13 \mathrm{ka}$ (maximum age of event E3) and $1.42 \pm 0.06 \mathrm{ka}$ (minimum age of event E1). Thus, we calculated two different apparent closed-cycle recurrence intervals and the average recurrence interval (McCalpin, 2009) between the events E3 - E1. To calculate the apparent closed-cycle recurrence interval for each earthquake cycle, we assumed that the most probable time of faulting is the mean between the minimum and the maximum limiting age for each event. Hence, the closed-cycle recurrence interval between events E2 $(3.29 \pm 0.07 \mathrm{ka})-\mathrm{E} 1(1.79 \pm 0.07 \mathrm{ka})$ and E3 $(4.68 \pm 0.09 \mathrm{ka})-\mathrm{E} 2$ are $1.50 \pm 0.10 \mathrm{ka}$ and 1.40 $\pm 0.12 \mathrm{ka}$, respectively. An average recurrence interval of $1.39 \pm 0.14$ ka may be calculated considering that the three events (E1, E2 and E3) occurred in the time span between $1.42 \pm 0.06 \mathrm{ka}$ and $5.59 \pm 0.13 \mathrm{ka}$. This value is in agreement with the estimated closed-cycle recurrence intervals. Evidently, the elapsed time since the event E1 is close to or has exceeded the estimated average recurrence interval for the GF.

Three different apparent slip rate estimates were calculated for this study, based on interseismic intervals between the E2-E1, E3-E2, and E3-E1 events. The E2-E1 cycle slip rate, based on the most recent event vertical displacement of $0.60 \mathrm{~m}$ and a closed-cycle interval of $1.50 \pm 0.10 \mathrm{ka}$, is $0.40 \pm 0.03 \mathrm{~mm} / \mathrm{yr}$. The E3-E2 cycle slip rate, based on the penultimate event vertical displacement of $0.60 \mathrm{~m}$ and a closed-cycle interval of $1.40 \pm 0.12 \mathrm{ka}$ is $0.43 \pm 0.04 \mathrm{~m} / \mathrm{yr}$. The E3-E1 average slip rate, based on the cumulative vertical displacement of $1.70 \mathrm{~m}$ and the interseismic time interval of $4.17 \pm 0.14 \mathrm{ka}$ (between the maximum age of event E3 and the minimum age of event E1), is 0.41 $\pm 0.01 \mathrm{~mm} / \mathrm{yr}$.

Since, the seismic history of the Gyrtoni Fault was not completely known our data expand the existing knowledge on the Holocene tectono-stratigraphy of this structure. The outcome of the present study can be useful for the assessment of the seismic hazard of the surveyed area.

\section{Acknowledgments}

This research project was implemented within the framework of the Action «Supporting Postdoctoral Researchers» of the Operational Program "Education and Lifelong Learning" and is co-financed by the European Social Fund (ESF) and the Greek State. The authors would like to thank C. Grützner and S. Valkaniotis whose comments helped to improve the manuscript.

\section{References}

Adamiec, G. and Aitken, M.J., 1998. Dose-rate conversion factors: update, Ancient TL, 16, 37-49.

Ambraseys, N.N. and Jackson, J.A., 1990. Seismicity and associated strain of central Greece between 1890 and 1988, Geophys. J. Int., 101, 663-708.

Caputo, R., 1990. Geological and structural study of the recent and active brittle deformation of the Neogene-Quaternary basins of Thessaly (Greece). In: Scientific Annals, Vol. 12, Aristotle University of Thessaloniki, Thessaloniki.

Caputo, R., 1995. Inference of a seismic gap from geological data: Thessaly (Central Greece) as a case study, Ann Geofisica, 38, 1-19.

Caputo, R. and Pavlides, S., 1993. Late Cainozoic geodynamic evolution of Thessaly and surroundings (central-northern Greece), Tectonophysics, 223, 339-362. 
Caputo, R. and Helly, B., 2005. Archaeological evidences of past earthquakes: a contribution to the SHA of Thessaly, Central Greece, J. Earthquake Eng., 9(2), 199-222.

Caputo, R., Bravard, J.-P. and Helly, B., 1994. The Pliocene-Quaternary tecto-sedimentary evolution of the Larissa Plain (Eastern Thessaly, Greece), Geodyn Acta, 7, 57-85.

Caputo, R., Piscitelli, S., Oliveto, A., Rizzo, E. and Lapenna, V., 2003. The use of electrical resistivity tomography in Active Tectonic. Examples from the Tyrnavos Basin, Greece, $J$. Geodyn., 36(1-2), 19-35.

Demitrack, A., 1986. The Late Quaternary geologic history of the Larissa Plain, Thessaly, Greece: Tectonic, Climatic and Human Impact on the Landscape, Ph .D. dissertation, Stanford University, CA. Ann Arbor, Michigan: University Microfilms.

Duller, G.A.T., 2003. Distinguishing quartz and feldspar in single grain luminescence measurements, Radiation Measurements, 37, 161-165.

Huntley, D.J., Godfrey-Smith, D.I. and Thewalt, M.L.W., 1985. Optical dating of sediments, Nature 313, 105-107.

IGME, 1985. Geological Map of Greece, Scale 1:50000, Sheets: Larissa, Gonni, Institute of Geology and Mineral Exploration, Athens.

McCalpin, J.P., 2003. Criteria for determining the seismic significance of sackungen and other scarp-like landforms in mountainous regions. In: Hart, E.W., ed., Ridge-Top Spreading in California: Contributions Toward Understanding a Significant Seismic Hazard: California Geological Survey, CD 2003-05, 2 CD-ROMs.

McCalpin, J.P., 2005. Late Quaternary activity of the Pajarito fault, Rio Grande rift of northern New Mexico, USA, Tectonophysics, 408, 213-236.

McCalpin, J.P., 2009. Application of Paleoseismic Data to Seismic Hazard Assessment and Neotectonic Research. In: McCalpin, J.P., ed., Paleoseismology, Academic Press, San Diego, $1-106$.

Murray, A.S. and Wintle, A.G., 2000. Luminescence dating of quartz using an improved singlealiquot regenerative-dose protocol, Radiation Measurements, 32, 57-73.

Murray, A.S. and Wintle, A.G., 2003. The single aliquot regenerative dose protocol: potential for improvements in reliability, Radiation Measurements, 37, 377-381.

Oliveto, A., Mucciarelli, M. and Caputo, R., 2004. HVSR prospecting in multi-layered environments: An example from the Tyrnavos Basin (Greece), Journal of Seismology, 8, 395406.

Pavlides, S.B. and Caputo, R., 2004. Magnitude versus faults' surface parameters: quantitative relationships from the Aegean, Tectonophysics, 380(3-4), 159-188.

Papaioannou, I., 1988. I seismiki istoria tis Larisas kata to 18 o kai 19o aiona [The seismic history of Larissa during the 18th and 19th centuries], Eleftheria Newspaper, August 7, 1988, Larissa (in Greek).

Prescott, J.R. and Hutton, J.T., 1994. Cosmic ray contribution to dose rates for luminescence and ESR dating: large depths and long-term time variations, Radiation Measurements, 23, 497-500.

RGAFJ (Research Group for Active Faults of Japan), 1992. Maps of active faults in Japan with explanatory test, University of Tokyo Press, Tokyo, $73 \mathrm{pp}$.

Schneider, H.A., 1968. Zur Quartargeologischen Entwicklungsgeschichte Thessaliens (Griechenland), R. Haber Verlag, 127 pp., 65 tabs., Berlin.

Schwartz, D.P. and Coppersmith, K.J., 1984. Fault behavior and characteristic earthquakes: examples from the Wasatch and San Andreas Fault Zones, J. Geophys. Res., 89(B7), 56815698.

van Andel, T.H., Zangger, E. and Demitrack, A., 1990. Land use and soil erosion in prehistoric and historical Greece, J. Field Archaeology, 17, 379-376.

Wells, D.L. and Coppersmith, K.J., 1994. New empirical relationships among magnitude, rupture length, rupture width, rupture area, and surface displacement, Bulletin of the Seismological Society of America, 84, 974-1002. 